ORIGINAL ARTICLE

\title{
Frequency of wound infection in children undergoing appendectomy for acute versus perforated appendicitis.
}

Sana Saeed ${ }^{1}$, Muhammad Sikander Ghayas Khan², Taimoor Hassan³, Ifzonia Babar ${ }^{4}$, Ghulam Mustafa Hingoro5 ${ }^{5}$ Syed Moin Islam ${ }^{6}$

Article Citation: Saeed S, Khan MSG, Hassan T,Babar I, Hingoro GM, Islam SM. Frequency of wound infection in children undergoing appendectomy for acuteversus perforated appendicitis. Professional MedJ2022;29(1):26-30. https://doi.org/10.29309/TPMJ/2022.29.01.6461

ABSTRACT... Objective: To find out the frequency of wound infection in children undergoing appendectomy for acute vs perforated appendicitis. Study Design: Observational and Cross-sectional study. Setting: Department of Surgery at Children's Hospital and the Institute of Child Health Lahore. Period: January 2018 to July 2018. Material \& Methods: Data was collected by using Random sampling technique. Patients of both genders were included. Diabetic children were excluded. Questionnaire was developed with the help of experts, literature review and data collection. Results: A sum of 120 patients were included with mean age of $9+1.94$ SD minimum was 7 and maximum was 13 . Some patients have acute appendicitis $20(16.67 \%)$ and 100 (80.33) perforated appendix undergone appendectomy. Conclusion: The findings of the study indicated that there is less wound infection in acute appendix but more wound infection observed in perforated appendix after appendectomy.

Key words: $\quad$ Appendicitis, Appendicectomy, Site Infection, Wound Infection.

\section{INTRODUCTION}

Acute appendicitis is a common condition that causes an acute abdomen. In the United States, 1000 cases are reported each day, and 355,000 patients every year. The etiology of appendicitis is still unknown; surgeons are and will continue to evaluate and treat appendicitis patients in the future. ${ }^{1}$ Pooled incidence of appendicitis was estimated during $21^{\text {st }}$ century per 100,000 person per year, which was higher in newly developed countries. In South Korea the pooled incidence rate was 206, in Turkey pooled rate was 106, in Chile it was 202. Asia. ${ }^{2}$ Practitioners diagnose appendicitis on the basis of their History, Examination and laboratory finding. Symptoms of appendicitis helps in the diagnosis. Common sign and symptoms include periumbilical pain radiating to right lower quadrant, abdominal rigidity are signs of appendicitis in adults. In the children Rovsing sign positive, a positive Psoas sign, absent or decrease bowel sound and a positive obturator sign reliable. ${ }^{3}$

Family history increase the risk of appendicitis three-fold. Environmental factor, Genetic factors: play the $30 \%$ role in enhancing appendicitis risk and infections with bacterial, viral, fungal, and parasitic were enhance the incidence of appendicitis. Data of 18,773 GWAS (genomewide association study) of appendectomy were analyzed, and compared with 114,907 controls. One locus had genome-wide significance. PITX2 gene was found protective effects against the appendicitis. ${ }^{4}$ No single strategies are present to diagnose and confirm the appendicitis. Children with suspected appendicitis should diagnose with combination of clinical signs and symptoms, laboratory finding of blood cell. The Magnetic resonance imaging and ultrasound provide farther evaluation and guide line for the management. ${ }^{5}$

1. BSc (Hons), Operation Theatre Technology, Lecturer, The University of Lahore, Pakistan.

2. MBBS, M.Phill (Bio-Chemistry), MS \& Ph.D The University of Lahore, Pakistan.

3. BSc (Hons), Department of Health Professional Technologies, The University of Lahore, Pakistan.

4. MBBS, DA (Consultant Anesthetist), Medical Director, Suleman Roshan Medical College, Tando Adam.

5. MBBS, MS (General Surgery), Senior Registrar, Suleman Roshan Medical College, Tando Adam.

\author{
Correspondence Address: \\ Dr. Taimoor Hassan \\ Department of Health Professional \\ Technologies, \\ The University of Lahore, Pakistan. \\ taimoorhassan408.th@gmail.com
}

Article received on:

$06 / 03 / 2021$

Accepted for publication:

$07 / 05 / 2021$ 
The treatment of acute appendicitis include antibiotic, analgesic, fluid resuscitation, and ultimately appendectomy. Normal saline was used for the resuscitation to correct the fluid deficiency on the bases of tissue perfusion and dehydration. In patients with severe dehydration and generalized peritonitis personalize electrolytes should be corrected accordingly. ${ }^{6}$

Due to the higher incidence of appendicitis and most frequently performed appendectomy procedure surgical treatment of appendix. This study was conducted to find out the wound infection in the perforated appendicitis and acute appendicitis. $^{7}$

Post-operative wound infection has been reported after the emergency surgery of appendicitis. Post-operative found infection of appendicitis influenced by multiple factors, the most important being surgical skill, technique and the criteria used to define the infection. ${ }^{8}$

During 1993 45.5\% of all emergency procedure at Mexico City General Hospital were appendectomy having most common complication was wound infection. Frequency of the wound infection were very high due to degree of operative contamination and various use of maneuvers to minimize contamination or to mitigate its consequences. ${ }^{9}$

Throughout years The American College of Surgeons the department of National Surgical Quality Improvement collects the data regarding post-operative abases and calculate the risk profile according to wound classification. They notified risk of wound infection goes up with increase of contamination. Rates have estimated between $1 \%-5 \%$ for clean wounds, while $3 \%-$ $11 \%$ for clean-contaminated wounds, $10 \%-17 \%$ for contaminated wounds, and more than $27 \%$ for infected/dirty wounds. Acute non-purulent infection or inflammation were found as a necrotic tissue without the evidence of purulent drainage (i.e.-dry gangrene). In a perforated appendicitis infected/dirty finding were present include perforation of bowel, peritonitis, abscess, rapture appendix and gangrene of gallbladder. ${ }^{10,11,12}$
Non-perforated and perforated appendicitis are termed as contaminated and clean-contaminated, correspondingly. Various studies have proved the efficiency of pre-operative prophylactic antibiotics in the reduction of post-op infectious complications caused after appendectomy. All the patients under goes appendectomy antibiotic were given as pre-operative to prevent the infection. Therefore, almost every patient who undergo appendectomy in our hospital are given with these preoperative prophylactic antibiotics. Patients with perforated appendicitis are often treated with a several course of postoperative therapeutic antibiotics because of higher contamination in peritoneal cavity and wound. . $^{13,14}$

The recurrence of wound infection right after the appendectomy is often related to the degrees/ severities of the appendicitis and are common in perforation. Therefore, it is salient to contrast the incidence of infection with clinical \& histological findings. In this group, the incidence of wound infection was $21.4 \%$ among 56 patients, where $41 \%$ occurred in perforation, the repercussions of perforated appendicitis rely on postoperative potential factors that includes; length of hospital stays, analgesia, return to regular activity and complications rate. $^{7}$ The relative incidence of wound infection in common appendix is supposedly due to contamination of peritoneum and wound during operation which shows to take care even for minor resections of intestine. Many workers showed reduction in the incidence of wound infection by using local application of antibiotic, antiseptics and povidone iodine which showed $21 \%$ wound infection in this study. ${ }^{15}$

Perforation was assessed on the basis of imaging and intraoperative and pathological reports of the patients. In the perforated appreciates complication were commonly found are intraabdominal abscess, acute gastroenteritis ileus and wound infection present up to 30 days of patient $1^{\text {st }}$ discharge. ${ }^{16}$ The objective of this study is to find out the frequency of wound infection in children undergoing appendectomy for acute vs perforated appendicitis. 


\section{MATERIAL \& METHODS}

This observational study was conducted on 120 patients from the department of pediatric surgery ward Children's hospital Lahore and institute of child health Lahore. This survey was conducted from January 2018 to July 2018. Both male and female children having wound infection were included in this study. The age of the children was between the 7 to 16 years. Patients having acute appendicitis and perforated appendix were included in the study. Diabetic children were excluded. Sample size were calculated on the bases of prevalence $8.7 \%^{12}$ of found infection in the appendix's surgery through online sample size calculator. ${ }^{13}$ Convenient sampling was used for data collection. Data was collected through Questionnaire developed from literature review and expert opinion. Researcher itself went to hospital and got the permission from hospital (IRB-UOL-FAHS/810/2021), describe about the study to the parents of children and gets the written consent of parents of children. Data was analyzed by SPSS 20 and references was given through End Note.

\section{RESULTS}

In our study the mean age of patients was 9 year. And observational study shows the result that there is less wound infection in acute appendicitis and more in perforated appendix.

Table-I showed mean age of Patient were 9.13 and stander deviation 1.94 .

\begin{tabular}{|l|c|c|c|}
\hline & Maximum & Minimum & $\begin{array}{c}\text { Mean } \pm \text { St. } \\
\text { Deviation }\end{array}$ \\
\hline $\begin{array}{l}\text { Age of } \\
\text { Participants }\end{array}$ & 13 & 7 & $9.13 \pm 1.94$ \\
\hline \multicolumn{2}{|r|}{ Table-I. Age of the Participants. } \\
\hline \multicolumn{2}{|c|}{} \\
\hline
\end{tabular}

Table-Il showed that most common symptom is Rovsing's sign 80(66\%) and tenderness 60(50\%). Most of the patient were presented perforated appendix 100 (83.3\%). 91 (75.83\%) were presented with severe pain. Mostly infection was developed at $3 \mathrm{dr}, 4^{\text {th }}$ and $5^{\text {th }}$ post optative days. Infection in Perforated appendix 20(16.66\%), 30(25\%), $34(28.33 \%)$ in Wound infection in acute appendix $6(5 \%), 6(5 \%), 8(6 \%)$ respectively.

\begin{tabular}{|c|c|c|}
\hline Questions & Category & Frequency \\
\hline \multirow{5}{*}{ Symptoms } & Vomiting & $12(10 \%)$ \\
\hline & Tenderness & $60(50 \%)$ \\
\hline & Pain on movement & $48(40 \%)$ \\
\hline & Roving's sign & $80(66 \%)$ \\
\hline & $\begin{array}{l}\text { Previous episodes of } \\
\text { similar pain }\end{array}$ & $20(16 \%)$ \\
\hline \multirow{2}{*}{$\begin{array}{l}\text { Wound } \\
\text { infection }\end{array}$} & Acute Appendix & $20(16.67 \%)$ \\
\hline & perforated appendix & $100(83.3 \%)$ \\
\hline \multirow{2}{*}{$\begin{array}{l}\text { Severity of } \\
\text { pain in post } \\
\text { appendectomy } \\
\text { patients. }\end{array}$} & Moderate & $29(24.16 \%)$ \\
\hline & Severe & $91(75.83 \%)$ \\
\hline \multirow{5}{*}{$\begin{array}{l}\text { Wound } \\
\text { infection in } \\
\text { perforated } \\
\text { appendix }\end{array}$} & $1^{\text {st }}$ post-operative day & $4(3.3 \%)$ \\
\hline & $2^{\text {nd }}$ post-operative day & $6(10 \%)$ \\
\hline & $3^{\text {rd }}$ post-operative day & $20(16.66 \%)$ \\
\hline & $4^{\text {th }}$ post-operative day & $30(25 \%)$ \\
\hline & $5^{\text {th }}$ post-operative day & $34(28.33 \%)$ \\
\hline \multirow{5}{*}{$\begin{array}{l}\text { Wound } \\
\text { infection in } \\
\text { acute appendix }\end{array}$} & $1^{\text {st }}$ post-operative day & $0(0 \%)$ \\
\hline & $2^{\text {nd }}$ post-operative day & $0(0 \%)$ \\
\hline & $3^{\text {rd }}$ post-operative day & $6(5 \%)$ \\
\hline & $4^{\text {th }}$ post-operative day & $6(5 \%)$ \\
\hline & $5^{\text {th }}$ post-operative day & $8(6 \%)$ \\
\hline \multicolumn{3}{|c|}{$\begin{array}{c}\text { Table-II. Symptom, severity of pain, and frequency of } \\
\text { wound infection. }\end{array}$} \\
\hline
\end{tabular}

\section{DISCUSSION}

Present study was conducted to find out the frequency of post-operative wound infection in patient with acute appendicitis and perforated appendix. For this purpose, 120 patients were selected, the mean ages of the patients were $9.13 \pm 1.94$. Study conducted in December 2012 highlighted that perforation rates were $86 \%$ in less than one year patient. Bansal S, enrolled 1 to 5 years old patients in the study and concluded that youngest children had fewer postoperative abscesses. ${ }^{17}$

In the present study researcher found the most common symptom was tenderness $60(50 \%)$ and pain was found in $48(40 \%)$ children presented with this symptom. When researchers performed Roving's sign, $80(66 \%)$ found positive. Another common symptom was vomiting 12 (10\%). Literature showed that review article on the children age 18 of below having possible appendicitis. Researcher In children with abdominal pain, fever 
was the single most useful sign associated with appendicitis. Researcher discussed the studies in which common symptom are abdominal pain, right lower quadrant (RLQ), Patients has complained of anorexia, emesis, nausea, vomiting, diarrhea, or dysuria. ${ }^{14}$ Another study discussed that anorexia, vomiting, severe-pain is common symptom respectively and the abdominal tenderness recorded in 27 patients, while peritonitis in (24), and temperature $38.0 \mathrm{C}$ and more $\mathrm{in}^{21}$, abdominal distension reported among ${ }^{18}$ were most common presenting signs. Different studies discussed the frequency of symptom and sequence of theses symptom use to from describe the likelihood ratio of appendicitis. ${ }^{18}$

The current study showed, of the 120 patients of appendectomy $100(83.3 \%)$ with perforated appendix and $20(16.67 \%)$ were with acute appendicitis. ${ }^{19}$

Research conducted on 198 children diagnosed with appendicitis in which $44(22.22 \%)$ patients were perforated appendix, 8 (18.18\%) patients had wound infection and others are delay wound closer group. ${ }^{19}$ One study was conducted regarding post-operative wound infection. 15 patients (3.7\%), including 6 cases of simple and 9 cases of gangrenous or perforated appendicitis which was not statistically significant. ${ }^{20}$ A Study conducted by Ming PC on one seventy-three patients, the researchers found that, the postop infections recurred in 40 patients (23.1\%). While 32 patients had common wound infections, 10 patients experienced postoperative intraabdominal abscess. Lastly, two patients experienced both infectious complications. ${ }^{21}$

Regarding post-operative wound infection in perforated appendix and acute appendicitis were developed on 3rd, 4th and $5^{\text {th }}$ day. In perforated appendix 20(16.66\%), 30(25\%), 34(28.33\%), and in acute appendicitis 6(5\%), 6(5\%), 8(6\%) respectively. If the wound infection developed within 30 days of operation on the post-operative, it includes in post-operative wound infection. Wound infection developed when microbiological flora were more the 10000 microorganisms per gram of tissue. ${ }^{22}$ Literature showed research conducted to compare difference between wound infection of open and laparoscopic appendectomy outcome patients operated with laparoscopically having less hospital stay and wound infection the on the hand patient operated with open procedure have long hospital stay and more frequency of wound infection. Operational procedure were effects on wound infection. ${ }^{23}$

\section{CONCLUSION}

Research concluded that common symptom of appendicitis was positive Rovsing's sign, tenderness, pain and vomiting accordingly. Patient's undergone appendectomy had acute appendicitis have low risk to developed wound infection as compare to perforated appendicitis.

\section{Copyright $\odot 07$ May, 2021.}

\section{REFERENCES}

1. Ferris M, Quan S, Kaplan BS, Molodecky N, Ball CG, Chernoff GW, Bhala N, Ghosh S, Dixon E, Ng S, Kaplan GG. The global incidence of appendicitis: A systematic review of population-based studies. Annals of surgery. 2017 Aug 1; 266(2):237-41.

2. Foul SA, Egozi E, Assalia A, Kluger Y, Mahajna A. Is early appendectomy in adults diagnosed with acute appendicitis mandatory? A prospective study. World Journal of Emergency Surgery. 2019 Dec 1; 14(1):2.

3. Rentea RM, Peter SD, Snyder CL. Pediatric appendicitis: State of the art review. Pediatric surgery international. 2017 Mar 1; 33(3):269-83.

4. Lipsett SC, Bachur RG. Current approach to the diagnosis and emergency department management of appendicitis in children. Pediatric Emergency Care. 2017 Mar 1; 33(3):198-203.

5. Stringer MD. Acute appendicitis. Journal of paediatrics and child health. $2017 \mathrm{Nov}$; 53(11):1071-6.

6. Parthiban N, Harish M. A study on microbiology culture of acute appendicectomy specimen and its correlation with wound infection. International Surgery Journal. 2017 Jun 22; 4(7):2212-5.

7. Rogers AP, Zens TJ, Leys CM, Nichol PF, Ostlie DJ. A call for a standardized definition of perforated appendicitis. Journal of pediatric surgery. 2017 Jan 1; 52(1):89-92. 
8. Sadraei-Moosavi SM, Nikhbakhsh $N$, Darzi AA. Postoperative antibiotic therapy after appendectomy in patients with non-perforated appendicitis. Caspian Journal of Internal Medicine. 2017; 8(2):104.

9. Kim JW, Shin DW, Kim DJ, Kim JY, Park SG, Park JH. Effects of timing of appendectomy on the risks of perforation and postoperative complications of acute appendicitis. World Journal of Surgery. 2018 May 1; 42(5):1295-303.

10. Noorit P, Siribumrungwong B, Thakkinstian A. Clinical prediction score for superficial surgical site infection after appendectomy in adults with complicated appendicitis. World Journal of Emergency Surgery. 2018 Dec $1 ; 13(1): 23$.

11. Sampsize. Philippe Glaziou; 2003-2005 [cited 2018 June2nd]; Available from: http://sampsize.sourceforge. net/iface/.

12. Pogorelic Z, Buljubasic M, Susnjar T, Jukic M, Pericic TP, Juric I. Comparison of open and laparoscopic appendectomy in children: A 5-year single center experience. Indian pediatrics. 2019 Apr 1; 56(4):299303.

13. CODA Collaborative. A randomized trial comparing antibiotics with appendectomy for appendicitis. New England Journal of Medicine. 2020 Nov 12; 383(20):1907-19.

14. Yang Z, Sun F, Ai S, Wang J, Guan W, Liu S. Metaanalysis of studies comparing conservative treatment with antibiotics and appendectomy for acute appendicitis in the adult. BMC surgery. 2019 Dec; 19(1):1-0.

15. Polites SF, Azarow KS. Perspectives on pediatric appendicitis and appendectomy during the severe acute respiratory syndrome coronavirus 2 pandemic. Journal of Laparoendoscopic \& Advanced Surgical Techniques. 2020 Apr 1; 30(4):356-7.
16. Fields AC, Lu P, Palenzuela DL, Bleday R, Goldberg JE, Irani J, Davids JS, Melnitchouk N. Does retrieval bag use during laparoscopic appendectomy reduce postoperative infection?. Surgery. 2019 May 1; 165(5):953-7.

17. Pogorelic Z, Buljubasic M, Susnjar T, Jukic M, Pericic TP, Juric I. Comparison of open and laparoscopic appendectomy in children: A 5-year single center experience. Indian pediatrics. 2019 Apr; 56(4):299-303.

18. Lasek A, Pędziwiatr M, Kenig J, Walędziak M, Wysocki M, Mavrikis J, Myśliwiec P, Bobowicz M, Astapczyk $\mathrm{K}$, Burdzel M, Chruściel K. The significant impact of age on the clinical outcomes of laparoscopic appendectomy: Results from the Polish Laparoscopic Appendectomy multicenter large cohort study. Medicine. 2018 Dec;97(50).

19. Wang D, Dong T, Shao Y, Gu T, Xu Y, Jiang Y. Laparoscopy versus open appendectomy for elderly patients, a meta-analysis and systematic review. BMC surgery. 2019 Dec;19(1):1-1.

20. Myrelid P, Landerholm K, Nordenvall C, Pinkney TD, Andersson RE. Appendectomy and the risk of colectomy in ulcerative colitis: A national cohort study. American Journal of Gastroenterology. 2017 Aug $1 ; 112(8): 1311-9$.

21. Dai L, Shuai J. Laparoscopic versus open appendectomy in adults and children: A metaanalysis of randomized controlled trials. United European gastroenterology journal. 2017 Jun; 5(4):54253.

22. Foul SA, Egozi E, Assalia A, Kluger Y, Mahajna A. Is early appendectomy in adults diagnosed with acute appendicitis mandatory? A prospective study. World Journal of Emergency Surgery. 2019 Dec; 14(1):1-4.

23. Yen YT, Loh EW, Tam KW. Effect and safety of peritoneal lavage for appendectomy: A meta-analysis. The Surgeon. 2021 Feb 13.

\begin{tabular}{|c|l|l|l|}
\hline \multicolumn{3}{|c|}{ AUTHORSHIP AND CONTRIBUTION DECLARATION } \\
\hline No. & \multicolumn{1}{|c|}{ Author(s) Full Name } & Contribution to the paper & Author(s) Signature \\
\hline 1 & Sana Saeed & Write-up. & \\
\hline 2 & M. Sikander Ghayas Khan & Review \& Discussion. \\
\hline 3 & Taimoor Hassan & Critical analysis \& final review. & \\
\hline 4 & Ghulam Mustafa Hingoro & Statistical analysis. & \\
\hline 5 & Syed Moin Islam & Statistical analysis. & \\
\hline
\end{tabular}

